\title{
Conhecimentos De Professores De Matemática Para O Ensino De Noções Relativas À Estatística Na Educação Básica
}

\author{
Teacher Knowledge For The Teaching Of Mathematics Of Notions Concerning Statistics \\ In Basic Education
}

\author{
Ruy César Pietropaolo* \\ Universidade Anhanguera de São Paulo - UNIAN/SP \\ Angélica da Fontoura Garcia Silva ${ }^{* *}$ \\ Universidade Anhanguera de São Paulo - UNIAN/SP \\ Marta Élid Amorim ${ }^{* * *}$ \\ Universidade Federal de Sergipe - UFS
}

\begin{abstract}
Resumo
Este texto tem o propósito de apresentar um estudo cuja finalidade foi investigar os conhecimentos de um grupo de professores de Matemática para ensinar conceitos concernentes à Estatística na Educação Básica e as concepções desses docentes sobre esse ensino. Esta investigação, que envolveu 16 professores do $6^{\circ}$ ao $9^{\circ}$ do Ensino Fundamental da rede municipal de uma cidade do litoral de São Paulo, precedeu uma formação continuada desse grupo. Os dados foram obtidos por meio de questionários e entrevistas. Para a análise dos dados, relativamente aos conhecimentos que deveriam ser de domínio do professor, foram consideradas categorias discutidas por Shulman. Quanto ao ensino de Estatística, este estudo está referenciado em Gal e Batanero. Em relação às concepções de professores sobre o ensino de Estatística, adotou-se o significado de Concepção atribuído por Ponte. As respostas dos professores revelaram certa inconsistência em relação ao domínio de conhecimentos de noções relativas à Estatística. Quanto às concepções sobre o ensino desse tema, os docentes demonstraram certo ceticismo em relação à necessidade e inclusão desse tema em todos os anos do Ensino Fundamental, devido à extensão dos conteúdos que devem ensinar e à não-importância que atribuem a esse tema.
\end{abstract}

Palavras-chave: Educação Matemática, Ensino de Estatística, Conhecimento de Professores de Matemática.

\footnotetext{
* Doutor em Educação Matemática pela Pontifícia Universidade Católica de São Paulo (PUC/SP). Coordenador do Programa de Pós-graduação em Educação Matemática da Universidade Anhanguera de São Paulo (UNIAN/SP), São Paulo, São Paulo, Brasil. E-mail: rpietropaolo@gmail.com.

** Doutora em Educação Matemática pela Pontifícia Universidade Católica de São Paulo (PUC/SP). Docente vinculada ao Programa de Pós-graduação em Educação Matemática da Universidade Anhanguera de São Paulo (UNIAN/SP), São Paulo, São Paulo, Brasil. E-mail: rpietropaolo@gmail.com.

*** Doutora em Educação Matemática pela Universidade Anhanguera de São Paulo (UNIAN/SP). Docente da Universidade Federal de Sergipe (UFS), vinculada ao Departamento de Matemática - Campus Itabaiana e Programa de Mestrado Profissional em Matemática em Rede Nacional (PROFMAT). Atualmente realiza estágio pós-doutoral na UNIAN/SP com bolsa CAPES. Itabaiana, Sergipe, Brasil. E-mail: martaelid@gmail.com.
} 


\begin{abstract}
This paper aims to present a study whose purpose was to examine the knowledge that a mathematics teachers' group used to teach concepts related to statistics at elementary school levels and this group's conceptions about teaching this subject. This investigation preceded a continued development process of this group, which involved 16 teachers of the municipal school network of a coastal city in the state of Sao Paulo. Data was collected through questionnaires and interviews. For data analysis regarding the knowledge categories that teachers should master, Shulman's categories were used. As for the teaching of statistics, this study is based on Gal and Batanero. Regarding the teachers' conceptions on the teaching of statistics, we adopted the meaning of Conception as defined by Ponte. Teachers' answers revealed some inconsistency regarding the mastering of knowledge of notions related to statistics. As for the conceptions about its teaching, the teachers showed a somewhat skeptical view regarding the need for including statistics in all grades of elementary school, due to the size of the syllabus content they must cover and the non-importance they attribute to this subject.
\end{abstract}

Keywords: Mathematical education, Statistics teaching, Teachers knowledge of Mathematics.

\title{
1 Contexto Da Pesquisa
}

Este artigo apresenta os resultados de uma pesquisa que integra um conjunto de investigações sobre conhecimentos e práticas de professores da Educação Básica desenvolvidas por docentes de um Programa de Pós-Graduação, no âmbito de um projeto financiado pela Capes, denominado Observatório da Educação.

Docentes desse programa conceberam o projeto com o objetivo de constituir um grupo colaborativo de formação e pesquisas, cuja finalidade é promover e analisar o conhecimento e o desenvolvimento profissional de professores ou de futuros professores de matemática quando inseridos em processos de implementação de inovações curriculares e de reflexão sobre práticas docentes. A partir de 2013, pesquisadores participantes deste grupo, incluindo uma docente de outra universidade, propuseram realizar pesquisas de modo a contribuir para propostas de apoio efetivo ao trabalho do professor da Educação Básica com um tema específico: processo de ensino e de aprendizagem de noções concernentes à Probabilidade e Estatística.

No que se refere à presente pesquisa, foram envolvidos 16 professores de Matemática da rede pública municipal de uma cidade do litoral de São Paulo. Este estudo, realizado em março de 2018, precedeu uma formação continuada com esse grupo, cujo objetivo foi discutir indicações da Base Nacional Comum Curricular - BNCC (Brasil, 2018) - para o ensino e a aprendizagem de noções relativas à Estatística, incluindo a elaboração de situações de aprendizagem que facilitassem o desenvolvimento de habilidades apresentadas nessa Base. Deste modo, para conceber o processo formativo foi necessário que identificássemos conhecimentos e concepções dos docentes participantes para o ensino de conceitos e 
procedimentos concernentes à Estatística. Neste artigo são apresentados e discutidos os resultados dessa primeira fase da pesquisa, que denominamos de diagnóstica.

Reconhecemos que diagnósticos sobre conhecimentos de professores para o ensino vêm sendo amplamente discutidos em teses, como a defendida Corbo (2012) e apresentados em artigos como o de Campos e Pietropaolo (2013) e que há necessidade de ampliar e aprofundar ainda mais outros tipos de estudo, como os que analisam a incorporação de inovações curriculares nas práticas docentes.

Apesar disso, tendo em vista que a BNCC (Brasil, 2018) indica Estatística e Probabilidade ao longo da Educação Básica, consideramos ainda relevante apresentar estudos sobre conhecimentos e concepções de professores a respeito do ensino desse tema de modo a compreender quais tipos de formação docente são necessários para atender às demandas.

Em síntese, este estudo tem por objetivo analisar a base de conhecimentos de um grupo de professores de Matemática para ensinar noções, conceitos e procedimentos relativos à Estatística ao longo do Ensino Fundamental e as concepções desses professores sobre a necessidade do ensino nesta etapa da Educação Básica.

É importante observar que, embora as noções de Probabilidade também tenham sido objeto de nossa investigação, optamos por apresentar neste artigo apenas interpretações referentes às reflexões sobre os conhecimentos e concepções do grupo de docentes no tocante à Estatística e seu ensino.

\section{Relevância Do Ensino De Estatística}

Gal (2004) assume que o letramento estatístico está intimamente relacionado à competência que o cidadão deve desenvolver para avaliar e interpretar criticamente informações estatísticas. Segundo esse autor, para que um cidadão possa ser considerado estatisticamente letrado, deve possuir uma base de conhecimentos que o possibilite organizar e comunicar de forma eficiente as informações coletadas em diferentes contextos, além de argumentar sobre a aceitação das conclusões fornecidas. Para ele, "letramento estatístico [...] é necessário para os adultos estarem plenamente conscientes das tendências e fenômenos de importância social e pessoal" (Gal, 2004, p.49).

Batanero \& Godino (2005) também consideram que o letramento estatístico é de suma importância, destacando que os próprios estatísticos defendem a Educação Estatística para todos os indivíduos, algo que vem ganhando apoio mais intenso dos educadores matemáticos. 
Esses pesquisadores defendem uma inserção cada vez maior da Estatística nos currículos de Matemática das escolas, a partir dos anos iniciais do Ensino Fundamental.

De fato, os currículos de Matemática de diversos países - Austrália, Estados Unidos, Singapura, Espanha, por exemplo - levam em conta esses princípios, ao indicarem o ensino de Estatística a partir dos primeiros anos de escolaridade. No Brasil, há agora indicações estritas para o ensino de Estatística nos currículos dos estados e municípios: a BNCC (Brasil, 2018) adota a Estatística Probabilidade como uma das cinco unidades temáticas obrigatórias para organizar os objetos de conhecimento e as habilidades a serem desenvolvidas ao longo dos nove anos do Ensino Fundamental.

Para exemplificar destacamos duas habilidades dessa Base, uma para o $1^{\circ}$ ano e outra para o $9^{\circ}$ ano:

(EF01MA22) Realizar pesquisa, envolvendo até duas variáveis categóricas de seu interesse e universo de até 30 elementos, e organizar dados por meio de representações pessoais. (Brasil, 2018, p. 279)

(EF09MA23) Planejar e executar pesquisa amostral envolvendo tema da realidade social e comunicar os resultados por meio de relatório contendo avaliação de medidas de tendência central e da amplitude, tabelas e gráficos adequados, construídos com o apoio de planilhas eletrônicas (Brasil, 2018, p. 317).

A comparação dessas duas habilidades pressupõe um trabalho intenso e sistemático em todo o Ensino Fundamental, ou seja, não é possível realizar um trabalho para desenvolver a habilidade proposta para o $9^{\circ}$ ano sem que os alunos tenham uma base de conhecimentos desenvolvida anteriormente.

Em relação ao ensino de Estatística e Probabilidade destacamos que há também certo consenso dos pesquisadores em relação aos estudos realizados sobre esse tema (Batanero \& Godino, 2005), indicando que a ênfase desse ensino recai, quase sempre, em memorização de procedimentos e que muitos docentes apresentam fragilidades na compreensão dos conceitos. Kataoka, Souza, Oliveira, Fernandes, Paranaíba \& Oliveira (2008), por exemplo, investigando o cenário do ensino dessa temática no Brasil, constataram que os professores normalmente têm formação em Probabilidade e Estatística na graduação, mas não desenvolveram conhecimentos específicos para a sua prática profissional no ensino destes conceitos. Igualmente, autores de outros países também consideram que os professores não têm formação adequada para ensinar nem conceitos estatísticos nem sobre probabilidade (Ortiz, Batanero \& Arteaga, 2012).

Podemos justificar, assim, a relevância da escolha do tema Ensino de Estatística para nossa investigação. Considerando ainda que os docentes participantes desta pesquisa e do processo formativo tinham como tarefa a implementação de um currículo fundamentado na 
BNCC (Brasil, 2018), em que noções de Estatística devem ser ensinadas em todos os anos do Ensino Fundamental, pode-se considerar como relevante e necessária a identificação sobre o que esses professores conhecem e pensam sobre o ensino deste tema.

\section{Fundamentação Teórica}

Justificamos neste item os marcos teóricos adotados para elaborar os instrumentos de coleta de dados desta pesquisa e sua posterior análise - Shulman (1986) e Ponte (1992). Justificamos também a opção por Gal (2004) e por Batanero (2011) a respeito do ensino de Estatística.

O pesquisador Lee Shulman, em artigo de 1986, discute que nos Estados Unidos as pesquisas sobre o corpo de conhecimentos necessários à docência e os processos de seleção e avaliação de professores não enfatizavam, por exemplo, questões sobre fontes de analogias, metáforas, exemplos e reinterpretações do docente em relação a conceitos; sobre a preparação que os professores possuem para conectar diversos conteúdos; ou ainda sobre como a estratégia pedagógica é comprometida quando o professor não apresenta competência e domínio em relação a certo conteúdo.

Essa não-ênfase foi nomeada por Shulman como paradigma perdido (Shulman, 1986, p. 7). Como alternativa para superar esse paradigma, o pesquisador propôs uma base de conhecimentos construída a partir do saber específico da disciplina.

Shulman (1986) afirma:

Professores precisam não somente ser capazes de definir para os estudantes verdades aceitas em um domínio do conhecimento. Eles precisam ser capazes de explicar porque uma proposição particular está sendo justificada, porque é conhecimento de valor, e como está relacionada com outras proposições, tanto dentro, quanto fora da disciplina, tanto na teoria, como na prática (p.9).

A contribuição de Shulman $(1986,1987)$, talvez seja a mais usada em trabalhos sobre a formação de professores, foi a formalização daquilo que ficou conhecido como Conhecimento Pedagógico do Conteúdo. Esse pesquisador considera que para ensinar as noções e conceitos fundamentais de uma disciplina são necessários conhecimentos sobre as formas mais úteis de representação

[...] as analogias mais poderosas, ilustrações, exemplos e demonstrações - numa palavra, os modos de representar e formular o tópico que o faz compreensível aos demais. Uma vez que não há uma única forma de representação, o professor precisa ter às mãos um verdadeiro arsenal de formas alternativas de representação, algumas das 
quais derivam da pesquisa enquanto outras têm sua origem no saber da prática (Shulman, 1986, p.9, tradução nossa).

Assim, em relação aos Conhecimentos do Professor necessários para o ensino, adotamos a base de conhecimentos defendidas por Shulman (1986) para uma boa prática docente, incluindo três domínios: Conhecimento Pedagógico do Conteúdo, Conhecimento Específico do Conteúdo e Conhecimento do Currículo.

Ball, Thames e Phelps (2008) relataram certo incômodo em relação ao pouco avanço teórico a respeito dos conceitos que Shulman enunciou em 1986 e 1987. Por esse motivo, retomaram os conceitos tentando refiná-los do ponto de vista do ensino da Matemática. Assim, esses autores com base em pesquisas sobre a observação da prática do ensino de matemática, identificam dois subdomínios do conhecimento pedagógico do conteúdo, propondo também um novo domínio de conhecimento sobre Matemática voltado para a tarefa de ensinar, chamado de conhecimento especializado do conteúdo. Os trabalhos de Ball, Thames e Phelps (2008) deram origem a outros trabalhos importantes como o de Godino (2009):

Do nosso ponto de vista, os modelos de "conhecimento matemático para o ensino" elaborado desde as investigações em educação matemática, incluem categorias muito gerais. Consideramos que seria útil dispor de modelos que permitam uma análise mais detalhada de cada um dos tipos de conhecimentos que se pode pôr em jogo em um efetivo ensino (proficiente, eficaz, idôneo) de matemática. Isto permitirá orientar um desenho de ações formativas e da elaboração de instrumentos de avaliação dos conhecimentos do professor de matemática (GODINO, 2009, p. 19)

Todavia, considerando que este trabalho discute os conhecimentos dos professores para conceber uma formação, consideramos suficientes e adequado os conceitos proposto por Shulman (1986), por entender que seus domínios são suficientes para a coleta e discussão dos dados.

Em relação a Concepção, outro construto que utilizamos neste artigo, convém explicitar o significado que adotamos tendo em vista os diferentes significados atribuídos a esse termo pelos pesquisadores. O sentido que atribuímos à concepção é o mesmo dado por Ponte (1992), que discute concepções de professores de matemática.

O interesse pelo estudo das concepções dos professores, tal como, aliás, pelo estudo das concepções de outros profissionais e de outros grupos humanos, baseia-se no pressuposto de que existe um substracto conceptual que joga um papel determinante no pensamento e na acção. Este substracto é de uma natureza diferente dos conceitos específicos - não diz respeito a objectos ou acções bem determinadas, mas antes constitui uma forma de os organizar, de ver o mundo, de pensar. Não se reduz aos aspectos mais imediatamente observáveis do comportamento e não se revela com facilidade - nem aos outros nem a nós mesmos. As concepções têm natureza essencialmente cognitiva. Actuam como uma espécie de filtro. Por um lado, são indispensáveis, pois estruturam o sentido que damos às coisas. Por outro lado, actuam 
como elemento bloqueador em relação a novas realidades ou a certos problemas, limitando as nossas possibilidades de actuação e compreensão. (Ponte, 1992, p. 1)

O significado dado por esse pesquisador à concepção pode ser compreendido como um substrato que tem um papel determinante no pensamento e na ação. Ponte ainda destaca que as concepções

formam-se num processo simultaneamente individual (como resultado da elaboração sobre a nossa experiência) e social (como resultado do confronto das nossas elaborações com as dos outros). Assim, as nossas concepções sobre a Matemática são influenciadas pelas experiências que nos habituámos a reconhecer como tal e também pelas representações sociais dominantes. A Matemática é um assunto acerca do qual é difícil não ter concepções. É uma ciência muito antiga, que faz parte do conjunto das matérias escolares desde há séculos, é ensinada com carácter obrigatório durante largos anos de escolaridade e tem sido chamada a um importante papel de selecção social. Possui, por tudo isso, uma imagem forte, suscitando medos e admirações. (Ponte, 1992, p. 1)

Batanero (2011), afirma que é necessário preparar melhor os professores de Matemática que vão ensinar Estatística na Educação Básica. Para essa pesquisadora a formação de professores geralmente está focada em melhorar o conhecimento dos professores no que diz respeito aos sentimentos, concepções ou atitudes dos professores.

Esse é um ponto importante, pois, embora os professores estejam dispostos a aprender e dedicar mais tempo ao ensino de estatísticas e reconhecer a importância prática da estatística, eles sentem que seus alunos experimentam maiores dificuldades em estatística do que em outros tópicos matemáticos e se consideram não muito bem. preparados para ajudar seus alunos a enfrentar essas dificuldades. O conhecimento de matemática dos professores desempenha um papel significativo na qualidade de seu ensino (Batanero, 2011, p. 4, tradução nossa),

Compartilhamos das ideias de Batanero (2011) de que os professores podem não ter aprendido o conteúdo de que precisam para ensinar (conhecimento do conteúdo específico) ou como ensinar (conhecimento pedagógico do conteúdo). Muitos professores demonstram ter dificuldades parecidas com os alunos em relação às ideias estatísticas fundamentais. Batanero (2011) cita pesquisas que professores não interpretavam gráficos corretamente e que confundiam média com mediana.

No Brasil há alguns trabalhos sobre esses temas. Citamos como exemplo, Sera (2016), que investigou a ampliação da base de conhecimentos de um grupo de professores de Matemática da Educação Básica para ensinar leitura e construção de gráficos estatísticos a alunos dos anos finais do Ensino Fundamental e do Médio. Para isso, foi realizada uma formação continuada, cujos pressupostos foram reflexões compartilhadas sobre o Letramento Estatístico e dificuldades de ensinar noções relativas ao tema. Antes de iniciar esse processo, os professores revelaram concepções inconsistentes a respeito da leitura e construção de gráficos e de seu ensino. Observou-se que o grupo de professores, no geral, não priorizava esse 
tema em suas aulas e não utilizava tecnologias digitais por não as dominar suficientemente.

Compartilhamos também do pressuposto de que os processos formativos de professores devem discutir concepções, métodos e processos para promover uma aprendizagem efetiva dos objetos que constituem um dado campo do saber (Shulman, 1986, 1987). Essa pressuposição também dá sustentação para que nos processos de formação continuada haja espaço para a discussão de aspectos do conteúdo que os professores vão ensinar, inclusive promovendo a sua ressignificação. Trata-se de aprender a ensinar Matemática e, para tanto, é evidentemente importante o domínio do conteúdo que se vai ensinar e, sobretudo, dispor de diferentes estratégias para o ensino.

Portanto, para conceber o curso de formação foi necessário investigarmos a base de conhecimentos dos professores sobre noções concernentes à Estatística e suas posições sobre a inclusão desse tema em todos os anos do Ensino Fundamental.

Quanto à fundamentação do ensino de Estatística optamos por Gal (2004) tendo em vista que as habilidades apresentadas na BNCC do Ensino Fundamental, segundo nossa análise, estão intimamente relacionadas ao Letramento Estatístico concebido por esse autor.

Desse modo, consideramos que o professor deve ter uma base de conhecimentos que o possibilite a selecionar e/ou elaborar situações de aprendizagem que leve o estudante a desenvolver o letramento estatístico segundo Gal (2004), ou seja, o aluno deve desenvolver habilidades de organizar e comunicar de forma eficiente as informações coletadas em diferentes contextos e argumentar sobre a aceitação das conclusões fornecidas.

\section{Procedimentos Metodológicos}

Esta pesquisa foi desenvolvida com a colaboração de um grupo de 16 docentes de Matemática que em 2017 atuavam nos anos finais do Ensino Fundamental de três escolas públicas, em um processo de formação continuada proposto pela Secretaria de Educação. Foi acordado com os professores participantes que, antes de iniciar o curso, eles deveriam responder individualmente às questões e problemas de dois questionários e que depois seriam entrevistados. Foram também informados que as respostas fariam parte dos dados de uma pesquisa sobre ensino de Estatística. Todos aceitaram participar voluntariamente da pesquisa e da formação.

Assim, aplicamos os dois questionários aos 16 professores, sete homens e nove mulheres. A média e a mediana das idades desses docentes eram respectivamente 33,8 e 32 
anos, variando de 26 a 49 anos. Nesse grupo apenas sete já haviam lecionado no Ensino Médio. Os dados dos questionários foram coletados em março de 2018 em duas sessões de duas horas cada uma.

O primeiro questionário teve a finalidade de levantar dados pessoais dos docentes e suas posições em relação à inclusão de conceitos estatísticos na prática curricular docente. Procurouse, assim, identificar os conhecimentos do professor sobre o currículo (Shulman, 1986) e suas concepções sobre a inclusão desse tema na prática escolar (Ponte, 1992). O segundo questionário teve por finalidade identificar conhecimentos do professor sobre o conteúdo (conceitos de Estatística) e os conhecimentos pedagógicos (Shulman, 1986).

Além dos questionários, planejávamos entrevistar todos os participantes tendo em vista que poderiam ser muito concisos em suas argumentações para justificar suas respostas às questões abertas. No entanto, consideramos suficiente entrevistar apenas oito dos dezesseis docentes: selecionamos aqueles que foram muito lacônicos em suas respostas (como "concordo", "não sei”, "não aprendi") ou para compreender a razão de terem efetuado determinados cálculos (por exemplo, calcular a média das frequências referentes à variável qualitativa). As entrevistas foram realizadas sempre no sentido de elucidar as posições e justificativas dos docentes referentes às respectivas respostas do questionário.

A elaboração desses questionários e das questões das entrevistas foi norteada basicamente pelos motes: o que sabem esses professores sobre Estatística, quais estratégias de ensino conhecem e quais as razões e a importância que atribuem ao ensino desse tema, particularmente no Ensino Fundamental. Reiteramos que as questões propostas tiveram a finalidade de investigar conhecimentos dos docentes segundo as categorias de Shulman (1986): conhecimento do conteúdo, conhecimento pedagógico do conteúdo e conhecimento curricular, além das concepções a respeito da inclusão da Estatística ao longo do Ensino Fundamental.

Assim, propusemos questões e problemas para identificar conhecimentos dos professores sobre Estatística e concepções a respeito do ensino: análise de gráficos, situações envolvendo medidas de tendência central e dispersão; objetivos do ensino de Estatística; posicionamento sobre o ensino de Estatística em todos os anos do Ensino Fundamental. Como não será possível apresentar neste texto a análise das respostas a todas as questões e problemas propostos, discutiremos aquelas que permitem fundamentar melhor nossas conclusões. 


\section{Análise E Discussão Dos Resultados}

Apresentamos, a seguir, nossa interpretação dos dados, permitindo o delineamento de conhecimentos dos professores participantes de nosso estudo, relativos à Estatística e ao seu ensino. Em geral, expomos aqui a análise das respostas que consideramos exemplares, nos questionários ou nas entrevistas, conforme representem a posição da maioria, permitindo ao leitor fazer algumas inferências.

\subsection{Sobre O Conhecimento Curricular Do Conteúdo}

Para identificar as concepções dos professores sobre a inclusão da Estatística em suas práticas docentes, isto é, propusemos as questões:

A BNCC indica que todos os alunos do Ensino Fundamental do $1^{\circ}$ ao $9^{\circ}$ ano devem desenvolver habilidades relativas à Estatística. Assim, os professores que ensinam matemática deverão incluir o ensino de noções e procedimentos estatísticos em todas os anos escolares. Qual é a sua posição sobre essa indicação? Procure argumentos que justifiquem sua resposta.

Você já ensinou Estatística? Em caso afirmativo, qual foi o conceito ensinado? E em qual(is) ano(s) escolar(es)?

(Questões do Questionário 1, 2018)

Todos os 16 participantes foram unânimes em considerar a Estatística no Ensino Fundamental como necessária, mas todos fizeram ressalvas. Afirmaram também que ensinam (ou já ensinaram) média. Apenas cinco indicaram gráficos. As falas dos professores 7 e 13 (P7 e P13) exemplificam o sentimento da maioria.

Acho importante a estatística porque ela está na vida dos alunos. Mas francamente em todos os anos? Não é demais? Temos muito conteúdo para ensinar. Eu procuro deixar mais tempo para ensinar álgebra, os alunos têm muita dificuldade. E geometria então? Então não sobra tempo para ensinar estatística e nem medidas. Eu já ensinei média aritmética, acho que no sexto ano.

(Resposta do professor P7, durante a entrevista).

Eu concordo com a Base. Eu li inteira. Apenas não concordo em todos os anos. É um exagero. A estatística aparece no livro didático que adotamos na escola na parte do tratamento da informação. Eu não consigo dar todo o conteúdo, por isso eu pulo. É muita álgebra que tenho de ensinar. Eu dou um pouco de estatística apenas quando sobra um tempinho ou faltam muitos alunos. Mas os gráficos são importantes porque eles vão aprender funções no Ensino Médio. Eu ensino sim: gráficos no $9^{\circ}$ ano e média aritmética e ponderada no $6^{\circ}$ ano.

(Resposta do professor P13, durante a entrevista).

As concepções dos professores a respeito da Estatística no currículo de Matemática, 
indicam que se trata de um tema que poderia ser abandonado dada a extensão dos conteúdos previstos nos currículos de Matemática, embora reconheçam sua relevância. Pelas respostas dos docentes pode-se inferir que a grande tarefa deles é ensinar Álgebra, pois todos apontaram que a ênfase do currículo deveria recair sobre essa unidade temática.

O entendimento de que não é possível implementar um ensino mais sistemático de conceitos e procedimentos estatísticos, devido a extensão dos conteúdos de Matemática, notadamente da Álgebra, parecem corroborar o que Ponte (1992) destaca sobre o papel das concepções como elemento bloqueador em relação a novas realidade, no caso a implementação de inovações curriculares

De fato, as recomendações dos PCN (Brasil, 1998) relativas à Estatística (Tratamento da Informação) parecem não ter sido incorporadas aos currículos praticados. Pode-se dizer, assim, que a tradição, bastante forte nos currículos praticados, está presente nas falas dos docentes, tendo em vista que nos programas prescritos anteriores à década de 1990, as ênfases recaíram, quase sempre, na Aritmética para os anos iniciais e na Álgebra para os anos finais.

Convém considerar que o currículo tem se mostrado uma invenção reguladora do conteúdo e das práticas envolvidas nos processos de ensino e aprendizagem. No entanto, para a implementação de inovações como o ensino de Estatística e de Probabilidade, há de se promover ações formativas, levando em conta pesquisas sobre ensino de probabilidade e estatística, para que os professores realmente se convençam sobre a necessidade de equilibrar as ênfases nas diferentes unidades temáticas e de mudar suas concepções a respeito da Matemática e de seu ensino.

Batanero (2019) em sua conferência denominada "Thirty years of stochatis education research: Reflections and challenges" afirma que

A pesquisa em educação estocástica está agora bem estabelecida na comunidade de educação matemática, devido à ampla atenção dada às estatísticas e probabilidade nos currículos escolares e universitários, a fim de responder à necessidade de capacitar todos os cidadãos e profissionais em alfabetização estatística e probabilística (Batanero, 2019, p.2, tradução nossa)

A pesquisa de Batanero, Burrill e Reading (2011) discute que a inclusão de um tópico no currículo não garante automaticamente seu ensino e aprendizagem de forma correta.

\subsection{Sobre O Conhecimento Específico Do Conteúdo}

Para a investigação do Conhecimento Específico do Conteúdo (Shulman, 1986) dos 
professores participantes foram propostas questões ou problemas sobre análises de diferentes tipos de gráfico, cálculo e interpretação das medidas de tendência central e do desvio padrão. Para tanto, propusemos entre outras as quatro questões seguintes:

1. Média e mediana têm o mesmo significado? Justifique sua resposta.

2. Certo cruzamento tem alto índice de acidentes de trânsito conforme pode ser constatado em uma amostra dos últimos seis meses: 5, 4, 5, 8, 6, 8. Calcule a média, a mediana, a moda e o desvio padrão.

3. Um professor aplicou uma mesma prova de língua portuguesa em duas turmas de estudantes (A e B). Com o objetivo de comparar o desempenho dos estudantes das duas turmas ele elaborou os dois gráficos a seguir.

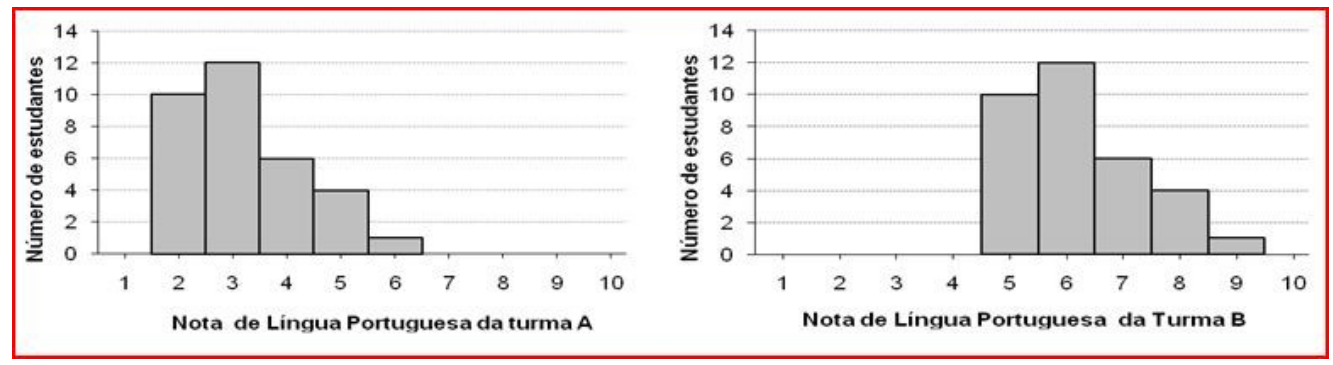

Número de alunos das turmas A e B segundo as notas em Língua Portuguesa

Os gráficos dos desempenhos dessas duas turmas têm exatamente a mesma forma. Além desse aspecto, o que essas distribuições têm em comum? O que têm de diferente? Justifique suas respostas.

4. Você está indeciso em comprar uma televisão e decide avaliar algumas informações estatísticas, fornecidas pelo fabricante sobre a duração (em horas) do tubo de imagem. Com que marca você ficaria? Justifique

\begin{tabular}{|l|c|c|c|}
\hline Marca da TV & $G A$ & $F B$ & $H W$ \\
\hline Média & 8000 & 8200 & 8000 \\
\hline Mediana & 8000 & 9000 & 7000 \\
\hline Desvio padrão & 600 & 1500 & 2500 \\
\hline
\end{tabular}

Atividade do livro Noções de Probabilidade e

Estatística de Magalhães e Lima (2011), p.126

(Questões do Questionário 2, 2018)

A respeito de média e mediana, apenas 2 dos 16 professores disseram que essas medidas tinham o mesmo significado. Dos outros 14 professores, oito escreveram argumentos do tipo:

Os significados são diferentes, pois as três palavras média, mediana e moda vêm sempre juntas. Eu não sei a fórmula para calcular mediana, mas sei que ela indica o meio e a média pode não ser no meio.

(Resposta ao questionário do professor P8)

Em relação ao cálculo das medidas proposto no segundo item, todos os 16 professores obtiveram corretamente a média, ao passo que apenas oito calcularam corretamente a mediana. 
Quanto à moda, dez docentes indicaram-na corretamente e três disseram que não tinha moda, provavelmente porque o conjunto era bimodal. Apenas um docente calculou corretamente o desvio padrão (P15), enquanto a maioria não respondeu ou disser que tinha esquecido a fórmula desse cálculo. Quatro docentes afirmaram que nunca haviam aprendido nem na escola nem na licenciatura.

Quanto aos gráficos das turmas A e B, na questão 3, esperávamos que os professores afirmassem, que o desvio padrão das duas turmas eram idênticos, ainda que as médias, medianas e modas fossem diferentes. No entanto, nenhum dos docentes fizeram menção ao desvio padrão. A explicação do professor P15, que inclusive acertou o cálculo do desvio padrão da questão anterior, exemplifica a posição dos demais.

Só as formas dos gráficos são iguais, o resto é tudo diferente. A média de A deve ser por volta de 3 enquanto a média de $B$ deve ser por volta de 6. As medianas e modas são também desiguais. (Resposta ao questionário do professor P15)

Como pretendíamos que os professores se referissem livremente às dispersões dos dados dos dois gráficos, optamos por não acrescentar uma questão sobre esse assunto e preferimos deixá-la para o processo formativo.

Quanto ao problema das marcas de TV, partimos do pressuposto de que os professores que dominassem os significados de média, mediana e desvio padrão argumentariam no seguinte sentido: as médias são próximas; HW deve ser descartada por possuir a menor mediana; FB tem uma vantagem por possuir a mediana mais alta, mas seu desvio padrão é 2,5 vezes maior do que o de GA, significando que sua variabilidade é maior; como GA não tem uma mediana muito mais baixa que a mediana de FB, então é possível indicar GA como a melhor opção.

No entanto, os argumentos utilizados pelos docentes estavam errados, inadequados ou inconclusivos. Dos 16 docentes, nove responderam FB, três responderam GA, três responderam HW e um não respondeu. Os que optaram por HW, o fizeram pelo maior desvio padrão. A maioria dos que escolheram FB argumentou que essa marca tinha a maior média e a maior mediana, sem observar o desvio padrão. As justificativas da escolha por GA não foram consistentes como, por exemplo, "a média e a mediana são iguais como tinham de ser" (resposta ao questionário 2 do professor P2).

Nossa análise indica que muitos dos docentes têm dificuldades a respeito das medidas de tendência central. Em relação à média, apesar de todos os professores terem acertado a primeira situação, dois deles consideraram média e mediana como sinônimos. Apenas a metade do grupo indicou corretamente a mediana. Seis professores não souberam indicar a moda.

As dificuldades de parte significativa dos professores em relação às medidas de 
tendência central estavam bastante próximas daquelas relatadas por Batanero (2000) a respeito dos erros dos estudantes do ensino básico como:

- Moda: adotar a maior frequência;

- Mediana: não ordenar os dados para calcular a mediana; calcular o dado central das frequências absolutas ordenadas de forma crescente.

Embora não tenhamos questionado diretamente os docentes a respeito dos significados de desvio padrão, é provável que eles os desconheciam, pois 13 docentes não fizeram menção ao desvio padrão para responder à Questão 4 e nenhum deles considerou o desvio padrão em suas respostas ao problema 1.

Batanero (2015) discute que conceitos estatísticos, mesmo os mais simples como a média, mediana e moda, têm significados complexos e, portanto, exige um ensino robusto ao longo do ensino básico de modo que os alunos ampliem progressivamente sua compreensão "progressão dos significados pessoais para os significados institucionais esperados". (Batanero, 2015, p.10)

\subsection{Sobre O Conhecimento Pedagógico Do Conteúdo}

Para investigar o conhecimento pedagógico do conteúdo (Shulman, 1986) e as concepções dos professores a respeito do ensino de noções concernentes à Estatística, propusemos, dentre outras, as questões que seguem.

1. Você já ensinou Estatística? Em caso afirmativo, quais são as estratégias ou recursos que você utilizou ou utiliza? Você utiliza softwares em suas aulas para construção de gráficos estatísticos?

2. No ensino da Estatística no EF, quais pontos você considera imprescindíveis?

3. Analise o gráfico a seguir

Gráfico 1: Cor preferida dos alunos

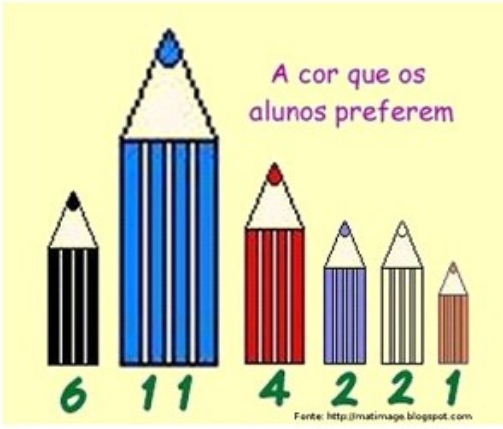

Fonte: Secretaria da Educação do Estado do Paraná 
Qual é o tipo desse gráfico? Ele é adequado? Está corretamente construido? Suponha que você vai apresentar esse gráfico aos seus alunos do EF do $8^{\circ}$ ou $9^{\circ}$ ano. Quais são as questões que você faria a esse grupo de alunos?

(Questões do Questionário 2, 2018)

Queremos destacar que os professores, de modo geral, foram bastante sucintos em suas respostas a todas essas questões. Afirmaram, de modo geral, que ensinavam gráficos de colunas e de setores no $9^{\circ}$ ano. Os argumentos recorrentemente utilizados foram similares a essa resposta:

Sim, lecionei estatística. Gráficos principalmente. Peço para resolverem alguns dos exercícios do livro e depois corrijo um a um na lousa. Acho sim importante o uso de computadores, mas na minha escola tem poucos e é dificil marcar hora. Também não sei usar planilhas, mas isso a gente aprende. Acho importante ensinar média e moda e construir gráficos.

(Resposta do professor P10, durante a entrevista)

Em relação à Questão 3, tendo em vista a frequência desse tipo de gráfico na mídia, esperávamos que os docentes identificassem que essa representação se trata de um pictograma, observando que as informações foram representadas de forma incorreta, o gráfico não respeita a escala, ou seja, as frequências de cada cor não correspondem aos tamanhos dos lápis. Por exemplo: como o lápis que indica 6 pode ser menor do que o que indica 4? Esperávamos que as propostas de atividades para os alunos fossem justamente para conduzir à questão da proporcionalidade, envolvendo a discussão sobre as áreas dos lápis e a proposição de um novo gráfico, além de corrigir o pictograma, utilizando inclusive a construção de gráficos por meio das tecnologias digitais.

Entretanto isso não ocorreu. Sobre a questão da adequação do gráfico, três professores responderam positivamente. Um deles registrou que o gráfico é de "fácil entendimento" (P6) e outro afirmou que "está corretamente construído se for corretamente analisado, as imagens são claras, maior frequência corresponde a maior área” (P3). Contudo, se for corretamente analisado, verificamos que ele foi incorretamente construído. Outro professor não justificou a resposta, mas sugeriu, de forma equivocada, que um gráfico de setores seria ainda melhor (P2).

Apesar de sete participantes responderem negativamente à questão da adequação, quatro não apresentaram justificativas relacionadas ao tamanho incorreto dos lápis para representar a preferência das cores. Os professores P4 e P9 criticaram a ausência dos eixos vertical e horizontal. Somente três docentes que responderam negativamente à pergunta mencionaram a escala como justificativa.

Há diferença entre espessura dos lápis, o que poderia gerar uma confusão, são dois atributos para a mesma variável. 
(Resposta do professor P7 ao questionário)

O professor P11 registrou que o desenho do lápis vermelho é maior que o preto, mas que pela preferência dos alunos esses tamanhos deveriam ser invertidos. Ele também afirmou que

Os lápis têm bitolas diferentes, seria interessante manter todos iguais.

(resposta do professor P11 ao questionário)

Em relação à proposta de elaboração de uma atividade para seus alunos, cada participante elaborou apenas duas ou três perguntas. Duas perguntas tiveram maior incidência (14 vezes cada uma): "Qual é a cor preferida dos alunos?" e "Quantos alunos foram pesquisados?" Consideramos que apenas essas questões propostas tornariam a atividade muito superficial para alunos do oitavo ou nono ano. Dois dos docentes (P6 e P13) propuseram a construção de uma tabela com frequências e inadequadamente solicitaram a média. O professor P13 ao ser interrogado durante a entrevista sobre o significado da média no contexto, respondeu:

Peço para calcularem a média somando os valores 6, 11, 4, 2, 2 e 1 e dividindo por 6, que é a quantidade de lápis. O significado é a média desses números. A moda é o 11.

Mediante a indagação do pesquisador, o docente ficou pensativo e depois respondeu

Não! A moda é o azul.

(Respostas do professor P13 à entrevista)

Esses professores deveriam ter elaborado outras questões, levando a um maior aprofundamento referente à leitura do pictograma, como a questão da proporcionalidade. A falta de conhecimento sobre essa temática provavelmente prejudicou a proposição de outras questões. Assim, pela fragilidade do conhecimento específico do conteúdo dos docentes, o conhecimento pedagógico desse conteúdo fica comprometido.

Concordamos com Batanero e Diaz (2010) por considerarem que o conhecimento matemático dos professores desempenha um papel significativo na qualidade da sua prática docente, pois favorece, por exemplo, a capacidade de utilizar em suas aulas diferentes registros de representação, de avaliar as estratégias das resoluções dos estudantes, de escolher livro didático, de compreender a razão dos objetos matemáticos a serem estudados e de formular questões que levem os alunos a relacionar suas concepções prévias a novos conceitos que serão abordados. Consideramos que os conhecimentos para desenvolver essas ações fazem parte do Conhecimento Pedagógico do Conteúdo.

De fato, para Shulman (1986) o Conhecimento Pedagógico de Conteúdo seria como uma mistura especial de conteúdo e pedagogia. Compartilhamos com esse autor que esse conhecimento vai além do conhecimento do conteúdo, pois deve abarcar várias explicações, 
analogias e ilustrações. Assim, saber a matéria a ser ensinada é necessário, embora não suficiente, para o desenvolvimento desse domínio de conhecimento do professor.

Ter o conhecimento das noções, conceitos e procedimentos estatísticos que se vai ensinar é fundamental para o professor desenvolver uma prática docente que promova o letramento estatístico segundo Gal (2004) e Batanero e Godino (2005). Reiteramos que os conhecimentos dos professores desta pesquisa não eram suficientes para promover esse letramento.

\section{Considerações Finais}

Como síntese de nossa análise, os resultados indicam que a grande maioria dos docentes participantes desta pesquisa tem pouco domínio de noções relativas à Estatística, como a identificação de erros em gráficos e significados das medidas de tendência central, notadamente a mediana. Mesmo em relação à média alguns docentes mostraram fragilidade ao proporem o cálculo dessa medida envolvendo variáveis categóricas.

Batanero e Diaz (2010) consideram que muitos professores inconscientemente compartilham uma variedade de dificuldades e equívocos com seus alunos a respeito de ideias estatísticas fundamentais.

Mediante a análise dos dados coletados na fase diagnóstica, interpretamos que a maioria dos docentes participantes considerava que os objetivos do ensino de Estatística no Ensino Fundamental deveriam ser restritos ao cálculo da média e à construção de gráficos.

Em nossa interpretação, as respostas dos professores não apresentaram argumentos que sustentassem a indispensabilidade do ensino de noções de Estatística ao longo do Ensino Fundamental. Eles ponderaram que o ensino da Estatística nos anos finais não poderia ocorrer tal como previsto na BNCC, pois isso diminuiria sensivelmente o tempo a ser dedicado para o ensino de outros temas como a Álgebra. Podemos dizer que as concepções desses professores podem ter agido, conforme Ponte (1992), como um filtro, estabelecendo limites para a reflexão que poderiam fazer.

Estamos de acordo com Batanero e Diaz (2010) que consideram que as concepções e crenças do professor merecem atenção muito especial, pois seu pensamento é fator chave, determinante, em um processo de inovação curricular em Matemática e podem determinar conhecimentos e concepções dos estudantes em relação à Matemática.

Os resultados desta pesquisa colocam em destaque a necessidade de promover 
discussões sobre a relevância da aprendizagem de noções e procedimentos concernentes à Estatística nos cursos de formação inicial e continuada, especialmente sobre as dificuldades vivenciadas pelos estudantes quando iniciam a construção desse conhecimento e sobre as concepções a respeito da importância de seu estudo nas diversas etapas da escolaridade. Além disso, há de se tomar decisões a respeito de metodologias que promovam a ressignificação dos conhecimentos do conteúdo específico, dos pedagógicos do conteúdo e dos curriculares relativos à temática.

Esta pesquisa poderá contribuir para os docentes desses processos formativos e para os pesquisadores em Educação Estatística de modo a ampliar a compreensão de conhecimentos específicos, pedagógicos e curriculares do conteúdo - dos professores de Matemática do Ensino Fundamental e Médio. Além disso, indica a necessidade de aprofundar o estudo sobre as concepções e crenças desses professores a respeito do ensino de Estatística nesta etapa escolar, de modo a conceber processos que visem mudanças em práticas docentes.

\section{Agradecimentos}

À CAPES, pelo financiamento do Projeto Observatório da Educação (OBEDUC) e concessão de bolsa do Programa Nacional de Pós-Doutorado (PNPD).

\section{Referências}

Ball, D. L.; Thames, M. H. \& Phelps, G. (2008). Content Knowledge for Teaching: what makes it special?. Journal of Teacher Education, v. 59(5), 389-407. Recuperado de http://citeseerx.ist.psu.edu/viewdoc/download?doi=10.1.1.493.2271\&rep=rep1\&type= pdf

Brasil. (2018). Ministério da Educação. Base Nacional Comum Curricular - Educação é a Base: Ensino Fundamental. Brasília: MEC. Recuperado de http://basenacionalcomum.mec.gov.br/images/BNCC_EI_EF_110518_versaofinal_site. pdf

Brasil. (1998) Ministério da Educação. Parâmetros Curriculares Nacionais Terceiro e Quarto Ciclos do Ensino Fundamental: Matemática. Brasília: MEC.

Batanero, C. Y \& Godino, J. (2005). Perspectivas de la educación estadística como área de investigación. In: R. Luengo (Ed.) Líneas de investigación en Didáctica de las Matemáticas (pp. 203-226). Badajoz: Universidad de Extremadura.

Batanero, C. y Díaz, C. (2010). Training teachers to teach statistics: what can we learn from research? Statistique et Enseignement, 1(1), 5-20. Recuperado de http://math.univlyon1.fr/irem/IMG/pdf/Batanero_Diaz.pdf. 
Batanero, C., Contreras, J. M. Y \& Arteaga, P. (2011). El currículo de estadística en la enseñanza obligatoria. EM TEIA Revista de Educação Matemática e Tecnologia Iberoamericana, $v$. 2(2), 1-20. Recuperado de

https://periodicos.ufpe.br/revistas/emteia/article/view/2151/1720

Batanero, C., Burrill, G., \& Reading, C. (2011). Overview: challenges for teaching statistics in school mathematics and preparing mathematics teachers. In C. Batanero, G. Burrill, \& C. Reading (Eds.), Teaching Statistics in School-Mathematics-Challenges for Teaching and Teacher Education: A Joint ICMI/IASE Study (pp. 407- 418), DOI 10.1007/978-94-0071131-0, Springer.

Batanero, C. (2015) Significado y comprensión de las medidas de posición central. Revista de Didáctica de las Matemáticas - UNO, v. 25, p. 41-58. Recuperado de https://www.ugr.es/ batanero/pages/ARTICULOS/isboa.pdf .

Batanero, C. (2019). Thirty years of stochastics education research: Reflections and challenges. En J. M. Contreras, M. M. Gea, M. M. López-Martín y E. Molina-Portillo (Eds.), Actas del Tercer Congreso Internacional Virtual de Educación Estadística. Recuperado de www.ugr.es/local/fqm126/civeest.html.

Campos, T. M. M. \& Pietropaolo, R. C. (2013). Um Estudo sobre os Conhecimentos Necessários ao Professor para Ensinar Noções Concernentes à Probabilidade nos Anos Iniciais. In: Borba, R., Monteiro, C. (Organizadores). Processos de Ensino e Aprendizagem em Educação Matemática. (pp. 55-91). Recife: UFPE.

Corbo, O. (2012) Um Estudo sobre os Conhecimentos Necessários ao Professor de Matemática para a Exploração de Noções Concernentes aos Números Irracionais na Educação Básica. Tese (Doutorado em Educação Matemática). Universidade Bandeirante de São Paulo. São Paulo.

Gal, I. (2004) Statistical Literacy: Meanings, Components, Responsibilities. In: BEM-ZIV, D., GARFIELD, J. The Challenge of Developing Statistical Literacy. (pp. 47-78). Dordrecht: Kluwer Academic Publishers.

Godino, J. D. (2009). Categorías de análisis de los conocimientos del profesor de matemáticas. Unión - Revista Iberoamericana de Educación Matemática, v. 20, 13-31. Recuperado de https://www.ugr.es/ jgodino/eos/JDGodino\%20Union 020\%202009.pdf

Kataoka, V. Y.; Souza, A. A.; Oliveira, A. de C. S.; Fernandes, F.; Paranaíba, P. \& Oliveira, M. S. (2008) Probability Teaching in Brazilian Basic Education: Evaluation and Intervention. Anais do ICME 11, Monterrey, Mexico. Recuperado de http://tsg.icme11.org/tsg/show/14.

Pino-Fan, L. R.; Godino \& J. D. (2015). Perspectiva ampliada del conocimiento didácticomatemático del profesor. In: Revista Paradigma, v. 36 (1), p. 87 - 109, jun. Recuperado de http://docente.ulagos.cl/luispino/wp-content/uploads/2015/07/2662-6235-1-PB.pdf

Ponte, J. P. (1992). Concepções dos professores de Matemática e processos de formação. In Brown, Margaret (Org.) Educação Matemática: Temas de Investigação. Portugal: Instituto de Inovação Educacional. (pp. 185-247). Lisboa: IIE. 
Sera, E. K. (2016) Conhecimentos de Professores para o Ensino da Leitura e Construção de Gráficos Estatísticos na Educação Básica. 2016. 215p. Dissertação (Mestrado em Educação Matemática). Universidade Anhanguera de São Paulo, São Paulo.

Shulman, L. S. (1986). Those Who Understend: Knowledge growth in teaching. Education Researcher. $\quad v$ 15.(2),.4-14, fevereiro. Recuperado de http://www.fisica.uniud.it/URDF/masterDidSciUD/materiali/pdf/Shulman 1986.pdf

Shulman, L. S. (1987) Knowledge and teaching: Foundations of the new reform. Harvard Educational Review, v. 57, 1-21. Recuperado de https://www.researchgate.net/publication/242473344_Knowledge_and_Teaching_Fou ndations_of_the_New_Reform

Submetido em: 28/03/2019

Aceito em 20/06/2019 